\title{
Proposed Configurations for the Use of Smart Dampers with Bracings in Tall Buildings
}

\author{
A. M. Aly Sayed Ahmed, ${ }^{1,2}$ Alberto Zasso, ${ }^{3}$ and Ferruccio Resta ${ }^{3}$ \\ ${ }^{1}$ Department of Mechanical Engineering, Faculty of Engineering, Alexandria University (on leave), Alexandria, Egypt \\ ${ }^{2}$ Department of Civil and Environmental Engineering, The University of Western Ontario, London, ON, Canada \\ ${ }^{3}$ Department of Mechanical Engineering, Politecnico di Milano, Milan, Italy
}

Correspondence should be addressed to A. M. Aly Sayed Ahmed, aly.mousaad@polimi.it

Received 30 June 2011; Revised 15 December 2011; Accepted 15 December 2011

Academic Editor: Marcelo A. Trindade

Copyright ( 2012 A. M. Aly Sayed Ahmed et al. This is an open access article distributed under the Creative Commons Attribution License, which permits unrestricted use, distribution, and reproduction in any medium, provided the original work is properly cited.

This paper presents wind-induced response reduction in a very slender building using smart dampers with proposed bracingslever mechanism system. The building presents a case study of an engineered design that is instructive. The paper shows that shear response and flexural response of tall buildings present two very different cases for vibration suppression. Smart dampers are implemented optimally in the building to reduce its response in the lateral directions for both structural safety and occupant comfort concerns. New bracings-lever mechanism configurations are proposed for the dampers to improve their performance. The study shows how the proposed configurations can enable application to flexural response and scenarios where the interstory drift is not enough for dampers to work effectively. In addition, a decentralized bang-bang controller improved the performance of the smart dampers.

\section{Introduction}

In tall buildings, wind-induced vibrations may cause annoyance to the occupants (especially in the upper floors), impaired function of instruments, or structural damage. Safer and more efficient designs are sought out to balance these issues with the reality of limited resources. Structural control can potentially provide more efficient structures. The purpose of structural control is to absorb and to reflect the energy introduced by dynamic loads. Passive, active, and semiactive types of control strategies have been proposed and implemented in a number of civil structures.

Although tuned mass dampers (TMDs) and active tuned mass dampers (ATMDs) are shown to be effective in reducing the response of tall buildings under wind loads [1-5], they are large, heavy, and take up valuable space buildings top. Moreover, they present additional cost to the project. Viscous dampers and semiactive dampers can be used as alternatives to overcome the difficulties associated with the application of TMDs and ATMDs. These devices do not require frequency tuning [6]. It is therefore sometimes possible to damp several modes with one device.
Smart damping technology is a type of semiactive control that employs variable dampers (e.g., variable orifice, magnetorheological fluid, and electrorheological fluid dampers). Smart damping technology assumes the positive aspects of both passive and active control devices; it can provide increased performance over passive control without the concerns of energy and stability associated with active control. Due to its low power requirements and fail-safe property, magnetorheological (MR) dampers have been shown to mesh well with application demands to offer an attractive means of protecting civil infrastructure systems against severe earthquake and wind loading [7-10]. MR damper is a kind of viscous damper, in which the viscous force generated in the damper can be controlled.

The challenge in using such devices for tall buildings is related to where to put the device in the building. In tall buildings, it is required that the damper is connected between two points where a significant displacement is expected. Unlike short and shear buildings, in which floor rotational angles are very small and there may be a significant interstory drift under dynamic loads, slender tall buildings may vibrate like a cantilever. Cantilever-like behavior of 


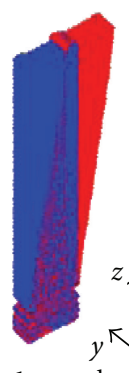

1st mode

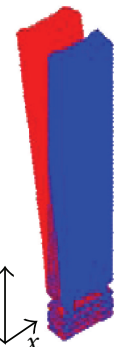

2nd mode $3 r d$ mode

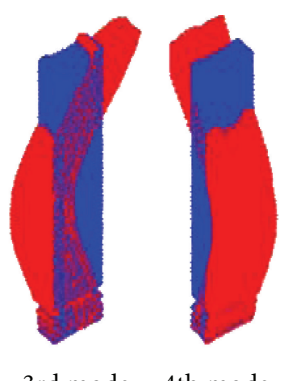

(a)

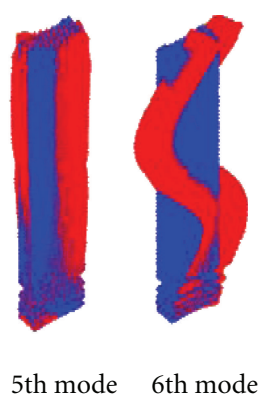

6 th mode

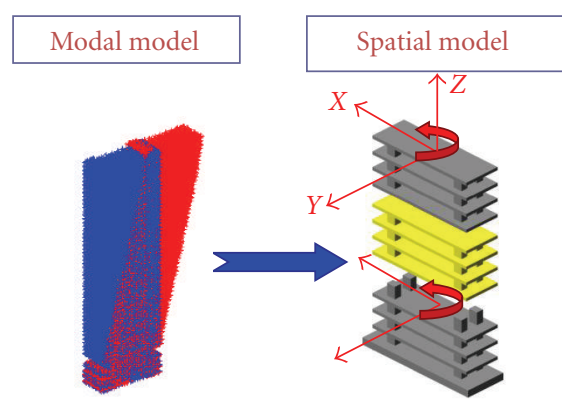

(b)

FIGURE 1: Finite element (FE) model of the tower with the coordinate system: the wind direction $0^{\circ}$ is along the $x$-axis.

buildings makes it very difficult to have an effective internal bracing system (interstory shear drift is usually not sufficient for a damper to work effectively).

Constantinou et al. [11] tested a motion amplification device called Toggle Brace Damper system (TBD) to amplify interstory motion. However, the efficiency of the TBD system is highly dependent on various local system parameters [12]. McNamara and Taylor [13] presented an application of toggle brace damper system in a high-rise structure to suppress the anticipated wind-induced accelerations. To provide some compactness to the TBD, Sigaher and Constantinou [14] introduced the scissor-jack-damper system. Berton and Bolander [15] described a displacement amplification device (DAD) based on a gear-type mechanism connected in series with a fluid viscous damper (FVD). Lee et al. [16] investigated the effectiveness of a toggle brace system that uses MR damper in a building structure for seismic response reduction. Walsh et al. [17] conducted numerical simulations to investigate scissor-jack dampers for controlling vibrations in a seismically excited flexible truss tower.

In this paper, the building under consideration is shown to behave in one lateral direction-like shear buildings ( $x$ direction) and in the other direction as cantilever structures ( $y$-direction). For the $x$-direction, internal bracings with MR dampers are used, while, for the $y$-direction, outer bracings with MR dampers are proposed. Since the displacement across the damper is shown to be small, a lever mechanism is proposed for motions magnification. Both passiveon and decentralized bang-bang controllers showed that MR dampers with the proposed bracings-lever mechanism configurations are effective in reducing the responses of the building under wind loads in the two lateral directions.

\section{Modeling of the Building}

The full-scale building has a height of $221.3 \mathrm{~m}$ above ground and a rectangular cross-section of $B / D=2.56(B$ : chord length, $D$ : thickness). The aspect ratio is about 10 , which makes it very slender and sensitive to strong winds. The overall buildings mass is about $1.4 \times 10^{5}$ ton. The structure has 50 stories above ground level. There are four underground stories. The first six modes of the building are shown in Figure 1(a). The first six natural frequencies are $0.122 \mathrm{~Hz}, 0.135 \mathrm{~Hz}, 0.461 \mathrm{~Hz}, 0.647 \mathrm{~Hz}, 1.079 \mathrm{~Hz}$, and $1.083 \mathrm{~Hz}$, respectively.

Although finite element software packages can help to provide mode shapes, modal masses, and modal frequencies for a desired number of modes, it does not provide information about damping in buildings. This is because, unlike mass and rigidities that are distributed along the elements, damping, however, is related to friction between joints and some hysteresis in the material and there is no convenient mean to refine the predictive capabilities regarding inherent structural damping, owing to its association with a number of complex mechanisms and even nonstructural elements.

While the best way to get information about damping is to go on site and measure it, there have been some efforts to develop empirical predictive tools for damping estimation based on full-scale observations $[6,18]$. Tamura and Yoshida [19] presented a damping predictor for tall buildings that is dependent on the vibrations amplitude. The formula for reinforced concrete buildings is given by

$$
\zeta=\frac{0.93}{H}+470 \frac{x_{H}}{H}-0.0018,
$$

where $\zeta$ is the first modal damping, $x_{H}$ is the displacement at the top of the building, and $H$ is the buildings height. For $x_{H}=0.5 \mathrm{~m}$ and overall building height of about $240 \mathrm{~m}$ (including underground stories), the damping factor from the above equation is about $1 \%$. For $x_{H}=0.25 \mathrm{~m}$ and $1 \mathrm{~m}$, the corresponding damping factors are $.5 \%$ and $2 \%$, respectively. However, the damping factor for the Isozaki tower is assumed to be $1 \%$. For control purposes, a lumpedmasses model is derived from the original FEM. In this model, the mass of the building is lumped at the positions of floors (Figure 1(b)). In general, equation of motion for an $n$ story building moving in both the two transverse directions and in torsion is written as

$$
\mathbf{M}_{\mathrm{s}} \ddot{\mathbf{x}}+\mathrm{C}_{\mathrm{s}} \dot{\mathbf{x}}+\mathbf{K}_{\mathrm{s}} \mathbf{x}=-\mathbf{F}+\boldsymbol{\Lambda} \mathbf{f},
$$

where $\mathbf{x}=[\mathbf{X Y} \Theta]^{T}$. The terms $\mathbf{X}=\left[\begin{array}{llll}x_{1} & x_{2} & \ldots & x_{n}\end{array}\right]$ and $\mathbf{Y}=\left[\begin{array}{llll}y_{1} & y_{2} & \ldots & y_{n}\end{array}\right]$ are row vectors of the displacements of the center of mass of each floor in the $\mathrm{x}$ and $\mathrm{y}$ directions, respectively, and $\boldsymbol{\Theta}=\left[\begin{array}{llll}\theta_{1} & \theta_{2} & \ldots & \theta_{n}\end{array}\right]$ is the vector of the rotations of each floor about the vertical axis ( $z$-axis), while 
$n$ is the number of stories. $\mathbf{M}_{s}, \mathbf{K}_{s}$, and $\mathbf{C}_{s}$ are mass, stiffness, and damping matrices, respectively.

The stiffness matrix of the spatial model is obtained by assuming the stiffness between floors as a combination of cantilever and shear rigidities. MATLAB codes [20] are written and used to derive the best stiffness matrix that gives the closest mode shapes to those of the FEM and the same first six natural frequencies.

The mass matrix $\mathbf{M}_{s}$ has the following form:

$$
\mathbf{M}_{s}=\left[\begin{array}{ccc}
\mathbf{M} & \mathbf{0} & \mathbf{0} \\
\mathbf{0} & \mathbf{M} & \mathbf{0} \\
\mathbf{0} & \mathbf{0} & \mathbf{I}
\end{array}\right],
$$

where $\mathbf{M}=\operatorname{diag}\left(\left[\begin{array}{llll}m_{1} & m_{2} & \ldots & m_{N}\end{array}\right]\right)$ is the diagonal $N \times N$ matrix of masses of each floor, and $\mathbf{I}=\operatorname{diag}\left(\left[\begin{array}{llll}I_{1} & I_{2} & \ldots & I_{N}\end{array}\right]\right)$, where $I_{i}$ is the moment of inertia of the $i$ th floor. $N=$ total number of floor. The stiffness matrix of the spatial model is obtained by assuming the stiffness between floors as a combination of cantilever and shear rigidities. MATLAB [20] codes are written and used to derive the best stiffness matrix that gives the closest mode shapes to those of the FEM and almost the same first six natural frequencies. The stiffness matrix $\mathbf{K}_{s}$ has the form

$$
\mathbf{K}_{s}=\left[\begin{array}{ccc}
\mathbf{K}_{x} & \mathbf{0} & \mathbf{0} \\
\mathbf{0} & \mathbf{K}_{y} & \mathbf{0} \\
\mathbf{0} & \mathbf{0} & \mathbf{K}_{\theta}
\end{array}\right],
$$

where $\mathbf{K}_{x}, \mathbf{K}_{y}$, and $\mathbf{K}_{\theta}$ are the stiffness matrices in the transverse directions ( $x$ and $y$ ) and the torsional direction, respectively.

The most effective way to treat damping within modal analysis framework is to consider the damping value as an equivalent Rayleigh Damping in the form of [21]

$$
\mathbf{C}_{s}=\alpha \mathbf{M}_{s}+\beta \mathbf{K}_{s},
$$

in which $\mathbf{C}_{s}$ is the damping matrix; $\alpha$ and $\beta$ are predefined constants. After having the damping matrix, the modal damping vector is calculated for all of the vibrational modes and the first six-modal damping is taken to be equal to a value of $1 \%$ which is the same value as assumed for the FEM. After adjusting the first six-modal damping factors, the damping matrix is reconstructed again. To obtain the damping matrix, $\mathbf{C}_{s}$, using modal damping factors [22], at normal modes (when the equations of motion are decoupled), the equations of motion for free damped vibration take the form

$$
\mathbf{M} \ddot{\mathbf{X}}+C_{D} \dot{\mathbf{X}}+\left[\omega^{2}\right] \mathbf{X}=0,
$$

where

$$
\mathbf{C}_{D}=[u u]^{T}\left[\mathbf{C}_{s}\right][u u]=2 \mathbf{M}_{s}[\omega][\zeta],
$$

in which $[u u]$ is the matrix of orthonormal modes associated with the eigenvalue problem (eigenvectors), $[\omega]$ is diagonal matrix of undamped natural frequencies, and $[\zeta]$ is a diagonal matrix of modal damping. In (2), the disturbance $\mathbf{F}=\left[\mathbf{F}_{x} \mathbf{F}_{y} \mathbf{T}\right]^{T}$ is a vector of excitation in which $\mathbf{F}_{x}$ and $\mathbf{F}_{y}$ are two vectors of the horizontal loads acting in the $x$ and $y$ directions, respectively, and $\mathrm{T}$ is a vector of the external torsional wind loads. Also, $\mathbf{f}$ is the vector of control forces, where its coefficient matrix $\Lambda$ is the matrix determined by the location of control devices.

Wind-loading vectors $\left(\mathbf{F}_{x}, \mathbf{F}_{y}\right.$, and $\left.\mathbf{T}\right)$ lumped at the position of floors are obtained from wind tunnel tests conducted at the wind tunnel of Politecnico di Milano [23] on a scaled 1:100 rigid model of the tower. The wind profile represents a typical urban terrain, as shown in Figure 2. The reference mean wind speed $\left(U_{\text {ref }}\right)$ was measured at a height of $1 \mathrm{~m}$. The target for the wind profiles is the Eurocode 1 [24]. The turbulence intensities in the longitudinal, lateral, and vertical directions are referred to by $\mathbf{I}_{u}, \mathbf{I}_{v}$, and $\mathbf{I}_{w}$, respectively. Further details about the wind tunnel experiment are given in Aly et al. [5]. Pressure data on the outer surface of the rigid model were acquired, and then the corresponding time histories of the wind excitation forces were calculated at the position of each floor.

The uncontrolled acceleration and displacement responses of the tower in the two lateral directions ( $x$-direction and $y$-direction) were evaluated for 16 different wind exposures. The response of the tower was shown to be out of the comfort limit. Wind loads at exposures corresponding to the maximum responses in the two lateral directions are considered in this paper (more description about wind loads estimation and the associated buildings response is provided in Aly [25]). A damping mechanism is needed for both safety and comfort reasons.

\section{MR Dampers}

An MR damper model with a maximum capacity of $1000 \mathrm{kN}$ is used in this paper. The MR damper is mathematically modeled using the Bouc-Wen model. This model was developed and shown to accurately predict the behavior of the MR damper over a wide range of inputs [26]. The equations governing the force, $f$, predicted by this model are as follows:

$$
f=c_{0} \dot{x}+\alpha z, \quad z=\gamma|\dot{x}| z|z|^{n-1}-\beta \dot{x}|z|^{n}+A \dot{x},
$$

where $z$ is the evolutionary variable that accounts for the history dependence of the response. The model parameters depend on the voltage, $v$, to the current driver as follows:

$$
\alpha=\alpha_{a}+\alpha_{b} u, \quad c_{0}=c x_{0 a}+c_{0 b} u,
$$

where $u$ is given as the output of the first-order filter

$$
\dot{u}=-\eta(u-v) .
$$

Equation (10) is used to model the dynamics involved in reaching rheological equilibrium and in driving the electromagnet in the MR damper. The parameters of the MR damper were selected so that the device could provide a capacity of $1000 \mathrm{kN}$ as follows: $\alpha_{a}=1.0872 \mathrm{e} 5 \mathrm{~N} / \mathrm{cm}$, 

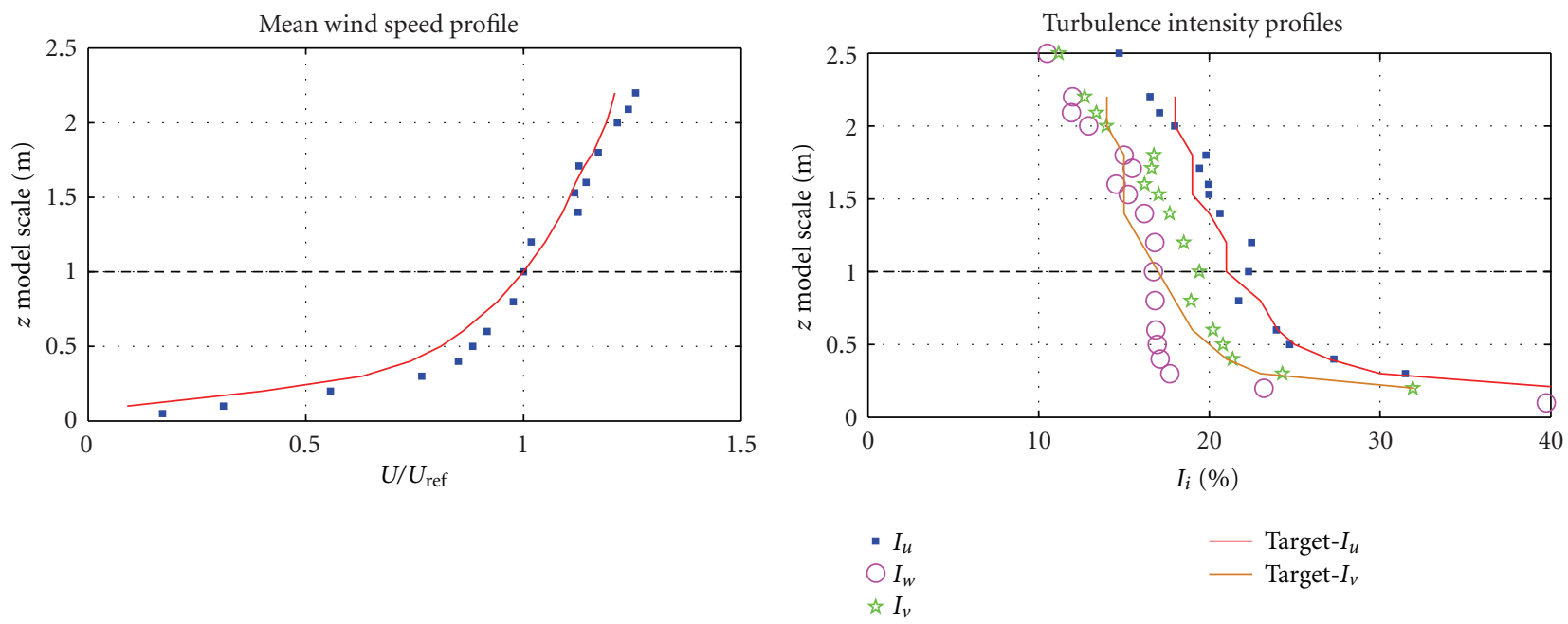

(a)

(b)

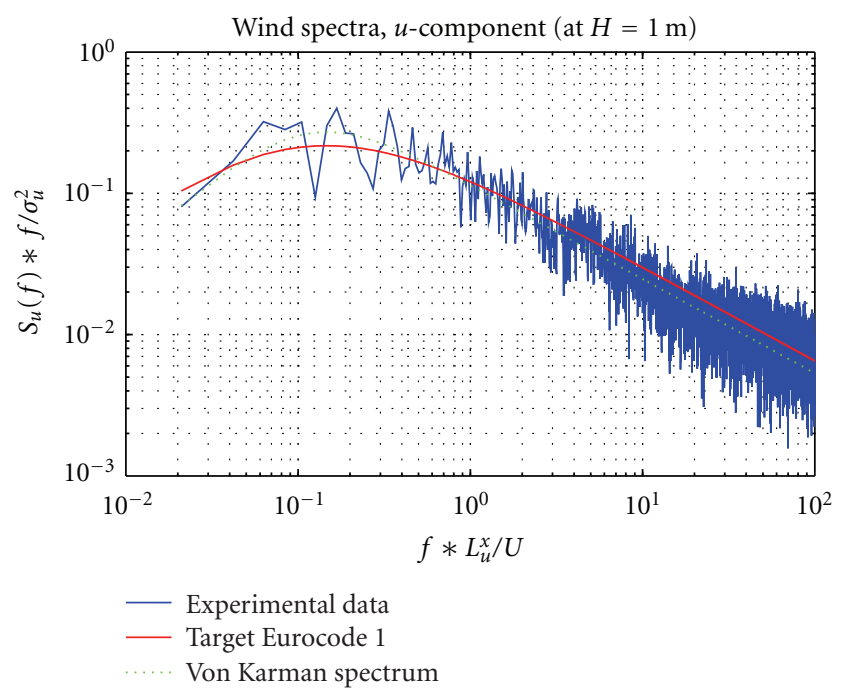

(c)

Figure 2: Mean wind speed profile, turbulence intensity profiles, and wind spectra. $U$ is the along wind mean wind speed, $U_{\text {ref }}$ is the reference mean wind speed, $I_{i}$ is the turbulence intensity, $f$ is the frequency, $S_{u}$ is the spectral density of the along wind velocity component, $\sigma_{u}$ is the root mean square value of the along wind velocity component, and $L_{u}^{x}$ is the along wind integral length scale.

$\alpha_{b}=4.9616 \times 10^{5} \mathrm{~N} /(\mathrm{cm} \cdot \mathrm{V}), \quad c_{0 a}=4.4 \mathrm{~N} \cdot \mathrm{s} / \mathrm{cm}, \quad c_{0 a}=$ $44 \mathrm{~N} \cdot \mathrm{s} /(\mathrm{cm} \cdot \mathrm{V}), n=1, A=1.2, \gamma=3 \mathrm{~cm}^{-1}, \beta=3 \mathrm{~cm}^{-1}$, $\eta=50 \mathrm{~s}^{-1}$ [27]. A Matlab-based SIMULINK model is built to simulate the MR damper model. The model is simulated under a sine wave input with a frequency of $0.1 \mathrm{~Hz}$ for different amplitudes $(0.01-0.1 \mathrm{~m})$ at 10 Volt, as indicated in Figure 3.

3.1. Decentralized Bang-Bang Control Algorithm. In this approach [28], the Lyapunov function was chosen to represent the total vibratory energy in the structure (kinetic plus potential energy), as in

$$
V=\frac{1}{2} \mathbf{X}^{T} \mathbf{K}_{s} \mathbf{X}+\frac{1}{2} \dot{\mathbf{X}}^{T} \mathbf{M}_{s} \dot{\mathbf{X}}
$$

Using (2), the rate of change of the Lyapunov function is then

$$
\dot{V}=\frac{1}{2} \mathbf{X}^{T} \mathbf{K}_{s} \dot{\mathbf{X}}+\dot{\mathbf{X}}^{T}\left(-\mathbf{C}_{s} \dot{\mathbf{X}}-\mathbf{K}_{s} \mathbf{X}+\mathbf{\Lambda} \mathbf{f}\right) .
$$

In this expression, the only way to directly effect $\dot{V}$ is through the last term. To achieve the goal of making $\dot{V}$ a large and negative (maximizing the rate at which energy is dissipated), the following control law is chosen:

$$
v_{i}=V_{\max } H\left(-\dot{\mathbf{x}}^{T} \boldsymbol{\Lambda} \mathbf{f}\right),
$$

where $v_{i}$ is the input voltage to the current driver of the $i$ th MR damper, $V_{\max }$ is the maximum allowable voltage, and $H(\cdot)$ is the Heaviside step function. Notice that this control law requires only measurements of the floor 
TABLE 1: Modal drifts normalized to be $1 \mathrm{~m}$ at the top of the building.

\begin{tabular}{|c|c|c|c|c|c|c|c|}
\hline \multirow{2}{*}{ Floors } & \multirow{2}{*}{ Height (m) } & \multicolumn{3}{|c|}{$x$-direction } & \multicolumn{3}{|c|}{$y$-direction } \\
\hline & & $L_{b}(\mathrm{~m})$ & $L_{b}^{\prime}(\mathrm{m})$ & $\delta(\mathrm{m})$ & $L_{b}(\mathrm{~m})$ & $L_{b}^{\prime}(\mathrm{m})$ & $\delta(\mathrm{m})$ \\
\hline Base-0 & 19.100 & 48.446 & 48.459 & 0.013 & 28.147 & 28.150 & 0.003 \\
\hline $0-6$ & 32.800 & 55.626 & 55.691 & 0.065 & 39.212 & 39.219 & 0.007 \\
\hline $6-11$ & 20.500 & 49.449 & 49.527 & 0.078 & 29.808 & 29.816 & 0.008 \\
\hline $11-16$ & 20.500 & 49.449 & 49.537 & 0.088 & 29.808 & 29.816 & 0.008 \\
\hline $16-21$ & 20.500 & 49.449 & 49.537 & 0.088 & 29.808 & 29.816 & 0.008 \\
\hline $21-26$ & 20.500 & 49.449 & 49.522 & 0.073 & 29.808 & 29.816 & 0.008 \\
\hline $26-31$ & 20.500 & 49.449 & 49.525 & 0.076 & 29.808 & 29.816 & 0.008 \\
\hline $31-36$ & 20.500 & 49.449 & 49.531 & 0.082 & 29.808 & 29.817 & 0.009 \\
\hline $36-41$ & 20.500 & 49.449 & 49.526 & 0.077 & 29.808 & 29.816 & 0.008 \\
\hline $41-46$ & 20.500 & 49.449 & 49.514 & 0.065 & 29.808 & 29.814 & 0.006 \\
\hline $46-50$ & 24.300 & 51.285 & 51.336 & 0.051 & 32.763 & 32.768 & 0.005 \\
\hline
\end{tabular}

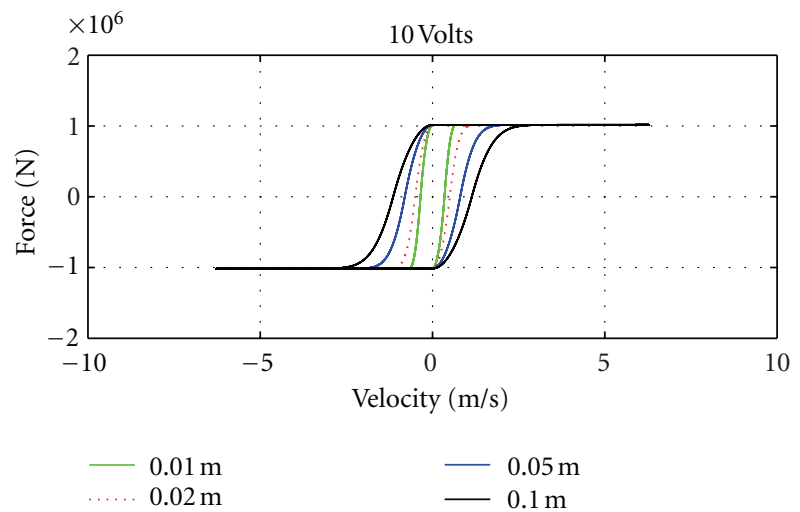

Figure 3: Comparison between the damper force under different amplitudes; $0.1 \mathrm{~Hz}$ sinusoidal displacement excitation at an input voltage of 10 volts.

velocities (only those in contact with the MR dampers) and applied control forces.

\section{Optimum Placement of Dampers}

4.1. Target Positions for the Dampers. Tall buildings usually have stiff stories, and the relative displacement between adjacent floors is usually small, which makes it difficult to put dampers between two successive floors. A good method to check drifts in tall buildings is to consider the first lateral mode shape in the direction where it is necessary to damp the vibrations. The floors that have reasonable shear drift may be selected for dampers to be mounted in between. Figure 4 is a schematic drawing of floors 16 and 21 before and after the first modal deformations. Modal deformations of the floors are normalized to be $1 \mathrm{~m}$ at the top of the tower and scaled up by 10 for better visualization. On the figure, $L_{b}$ is the diagonal (bracing) length before deformation and $L_{b}^{\prime}$ is the length after deformation, while $\alpha_{x}$ and $\alpha_{y}$ represent floors rotation angles in $x$-direction and $y$-direction, respectively. It is shown that $\alpha_{y}$ is much more than $\alpha_{x}$ which means that the floors are rotating much more in the $y$-direction. This is also related to the unequal aspect ratios which are about 3.8 in the $x$ direction and about 9.3 in the $y$-direction (the aspect ratio is calculated using the overall height of the tower including the underground floors).

Table 1 gives the first modal diagonal displacements between each two successive floors of "base, 0th, 6th, 11th, 16th, 21st, 26th, 31st, 36th, 41st, 46th, and 50th floors." The displacements are normalized to be $1 \mathrm{~m}$ at the top of the tower in each lateral direction. Again, one can see that the drifts in the $x$-direction are much more than those in the $y$-direction. By looking at the numbers of Table 1 and taking into account that there will be some elongations in the bracing member itself which will be considered negatives with respect to these numbers, the efficiency of the between floors dampers in the $y$-direction will be limited. However, the deformations in the $x$-direction (except the deformation between the base and the 0th floor) are large enough for dampers to work properly.

Based on the drift characteristics of the building in the two lateral directions, dampers may be placed between floors with internal bracings for vibration reduction in the $x$-direction. For vibration reduction in the $y$-direction, it may be placed with outer bracings. Figure 5 shows suggested positions for dampers placement in the $x$ - and $y$-directions.

4.1.1. Placement in the $x$-Direction. To know exactly which arrangement of dampers is the best, one may assume that ideal viscous dampers are placed between each two selected successive floors (those used in Table 1), then the modal damping factors of the building with dampers can be estimated analytically. Viscous dampers used are assumed to be linear, and their constitutional force deformation relationship may be expressed as

$$
F_{d}=C_{d} \dot{x}
$$

where $F_{d}$ and $x$ are the resistance force and deformation of the damper, respectively. $C_{d}$ is the damping coefficient of the viscous damper. Using the complex eigenvalue $\lambda$, the 


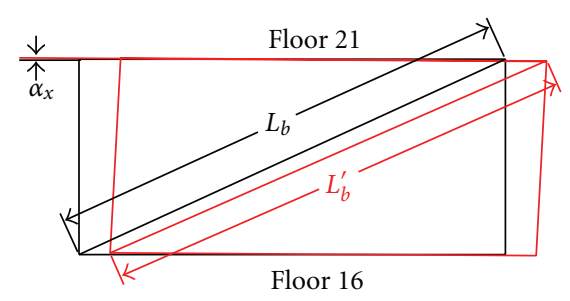

(a)

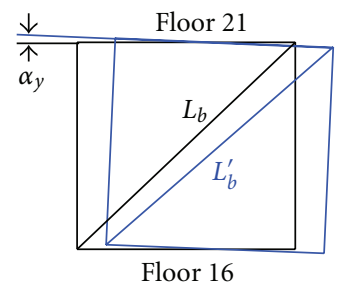

(b)

FIgURE 4: Modal deformations of floors number 16 and 21.

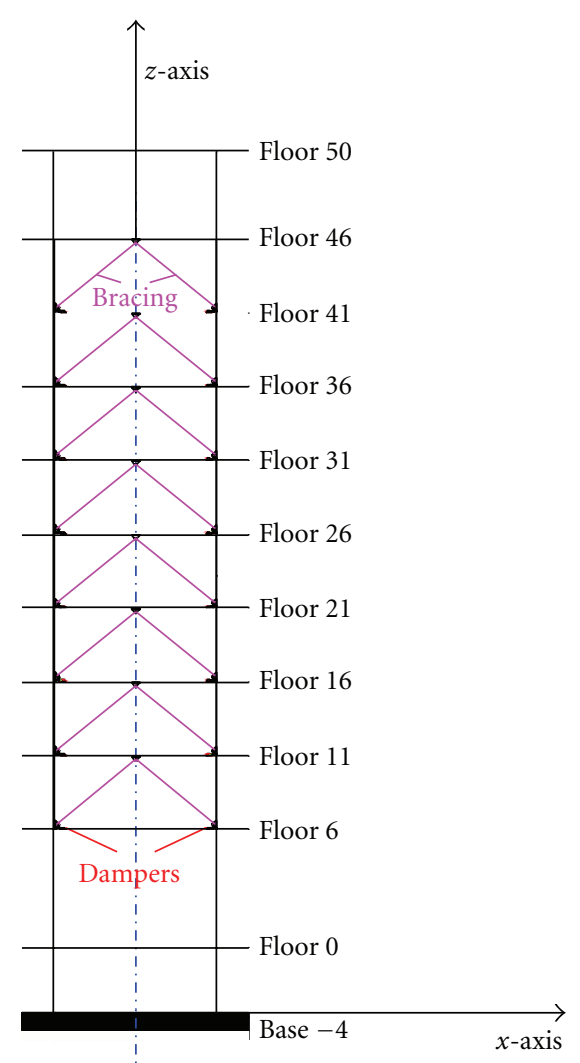

(a)

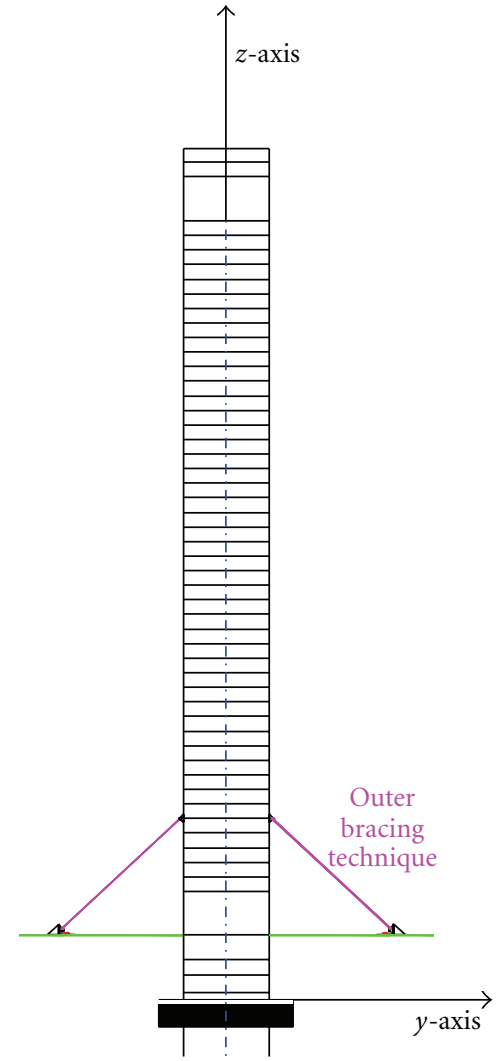

(b)

Figure 5: Suggested positions for dampers placement.

modal damping ratio, $\zeta$, is obtained as follows (concerning $i$ th mode):

$$
\lambda_{i}=\operatorname{Re}\left(\lambda_{i}\right)+j \operatorname{Im}\left(\lambda_{i}\right)=-\zeta_{i} \omega_{i}+j \omega_{i} \sqrt{1-\zeta_{i}^{2}},
$$

where $j=\sqrt{-1}$, "Re" refers to the real part, "Im" refers to the imaginary part, and

$$
\begin{gathered}
\omega_{i}=\sqrt{\operatorname{Re}\left(\lambda_{i}\right)^{2}+\operatorname{Im}\left(\lambda_{i}\right)^{2}}=\left|\lambda_{i}\right|, \\
\zeta i=\frac{-\operatorname{Re}\left(\lambda_{i}\right)}{\sqrt{\operatorname{Re}\left(\lambda_{i}\right)^{2}+\operatorname{Im}\left(\lambda_{i}\right)^{2}}}=-\operatorname{Re}\left(\frac{\lambda_{i}}{\left|\lambda_{i}\right|}\right) .
\end{gathered}
$$

First, optimization is based on viscous dampers, and, later, MR dampers will be used. Figure 6 shows the effect of dampers placement and their capacity on the first two lateral modal damping factors of the building in the $x$ direction. Due to the nature of the wind excitation and the fact that the first modal frequencies of the building are separated, the first mode is the most important one to be damped. On the figure, uniformly distributed case means that the total amount of damping equally distributed between stories. In this case, as indicated on the figure, it is not the most effective one if the target is to provide higher damping to the first mode. Dampers position "between base and 0th story" is providing little amount of damping, especially for the first mode, which is better to exclude this position. Dampers positions "between 11th and 16th" and "between 16th and 21st" are shown to provide higher amount of damping to the first mode. Dampers position 

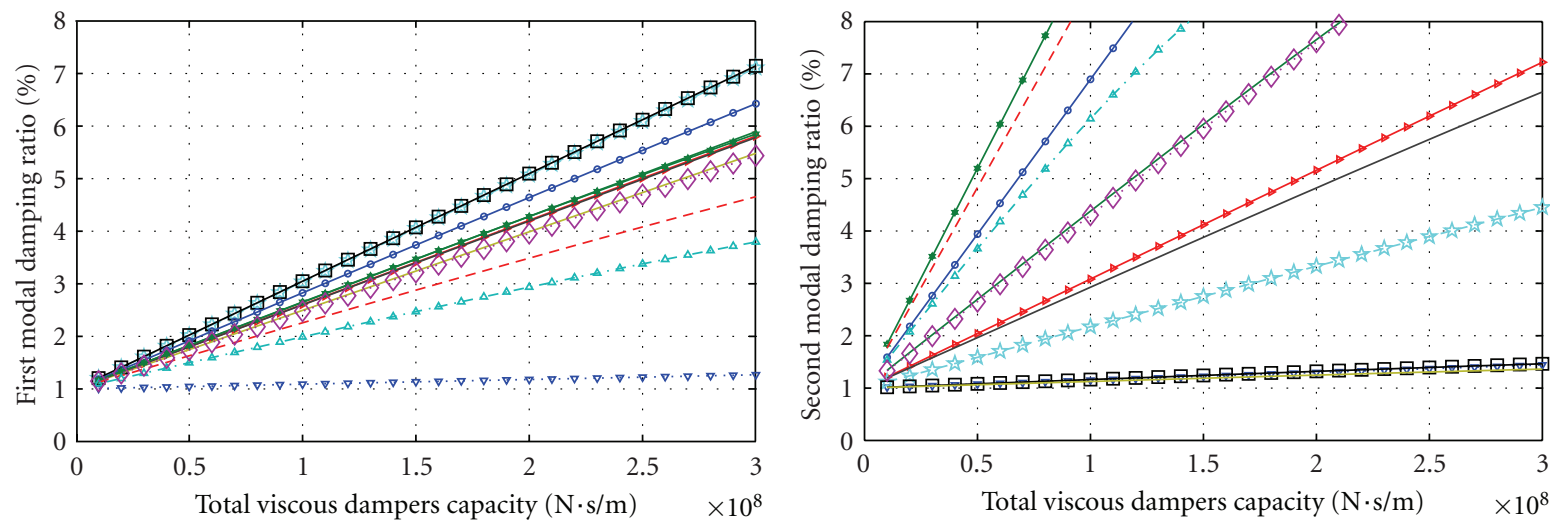

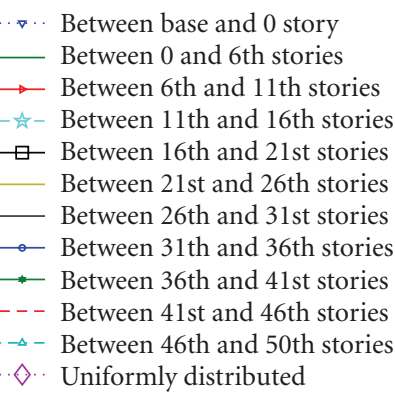

(a) $\cdots \nabla \cdots \quad$ Between base and 0 story

— Between 0 and 6th stories

$\rightarrow$ Between 6th and 11th stories

- - Between 11th and 16th stories

$\square$ Between 16th and 21st stories

_ Between 21st and 26th stories

- Between 26th and 31st stories

$\rightarrow$ Between 31th and 36th stories

-- Between 36th and 41st stories

- - - Between 41st and 46th stories

$-\Delta-$ Between 46th and 50th stories

$\diamond$. Uniformly distributed

Figure 6: Modal damping ratio versus total capacity of viscous dampers ( $x$-direction).

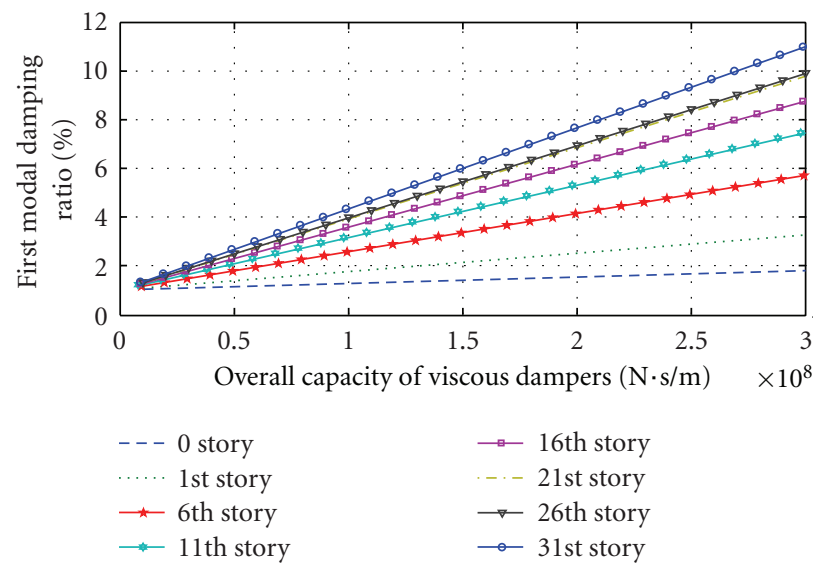

(a)

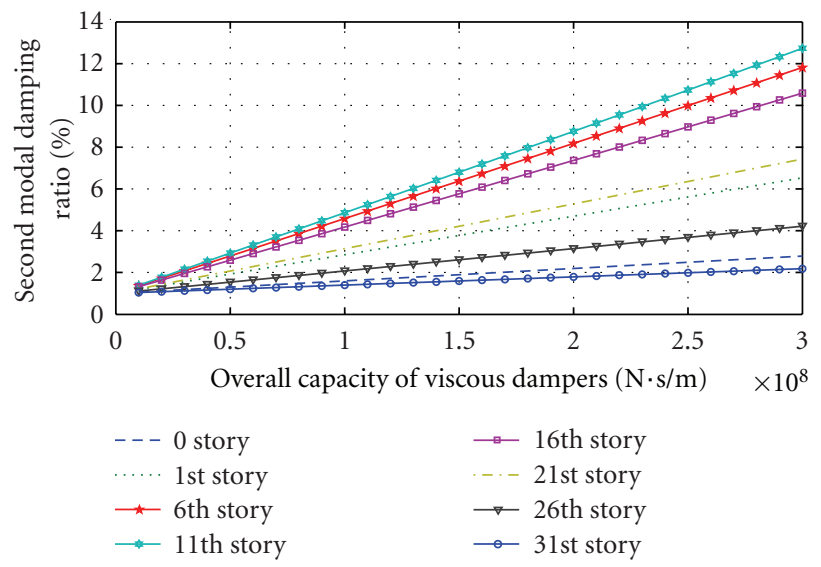

(b)

Figure 7: Modal damping ratio versus total capacity of viscous dampers ( $y$-direction).

"between 16th and 21st" provides slightly higher damping to the first mode than dampers position 11th and 16th." However, dampers position "between 11th and 16th" can provide higher damping in the second mode than dampers position "between 16th and 21st," which may be better for higher frequency excitations (e.g., earthquakes).

4.1.2. Placement in the $y$-Direction. The placement of dampers in the $y$-direction is between floors and ground as indicated on Figure 5(b). The point of fixing the damper with ground is considered to be unchangeable, while the optimum position to which the other part of the link is to be connected is to be found. Eight different bracing positions including between ground and one of the stories number 0 , $6,11,16,21,26$, and 31 are considered. Figure 7 gives the first two lateral modal damping factors of the building in the $y$-direction against dampers capacity for different bracing positions. It is shown that as the link is connected to higher stories the first modal damping is increasing. However, the highest amount of damping to the second mode is provided when the link is connected between ground and the 11th story. 


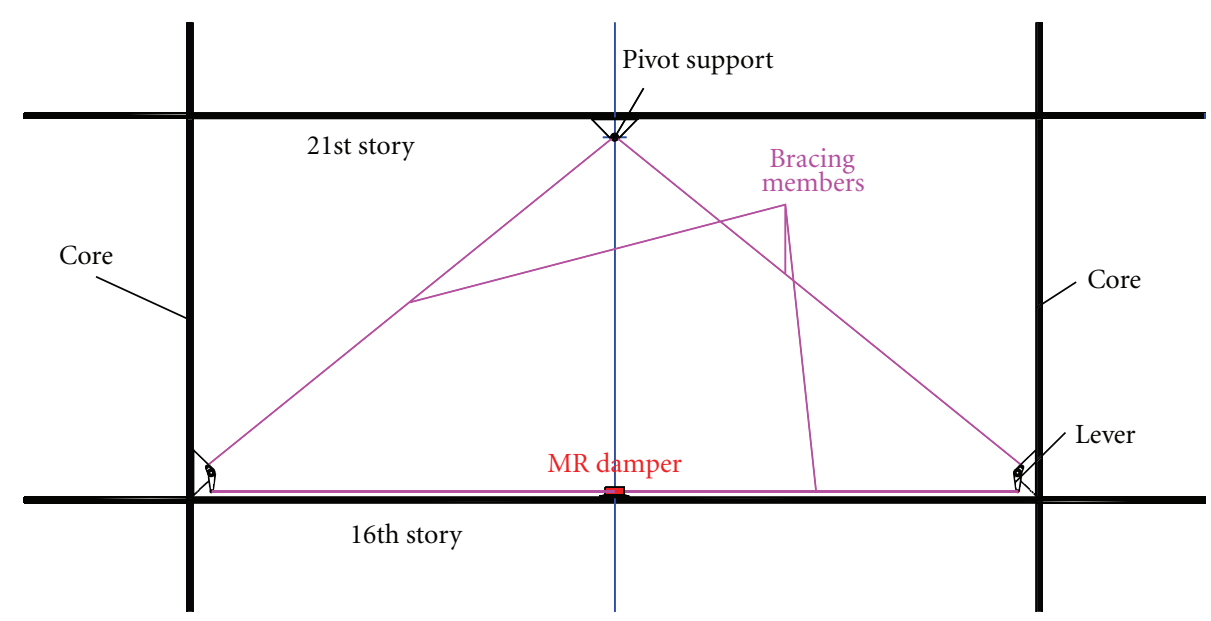

(a)

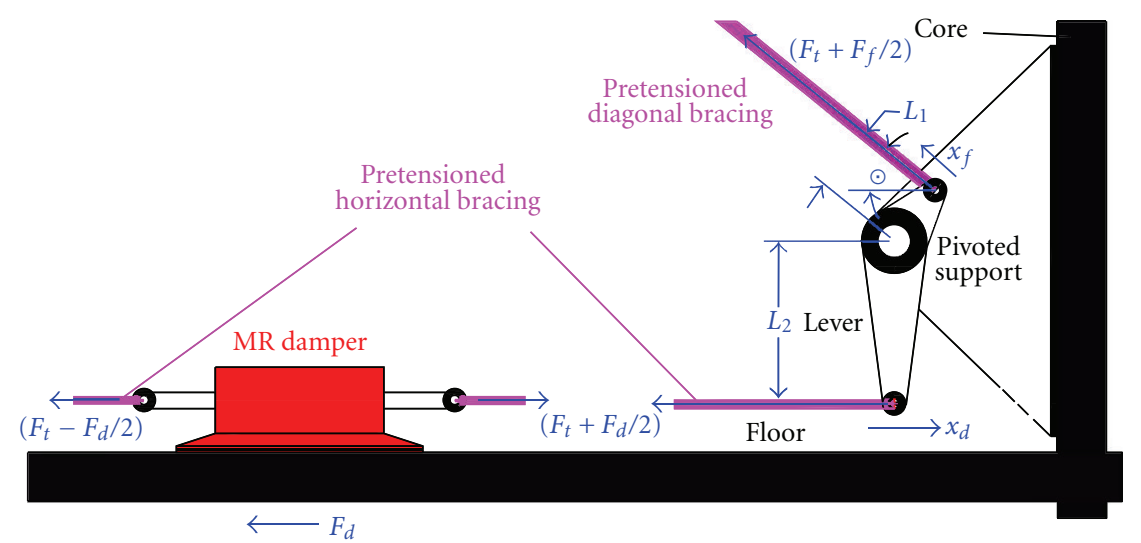

(b)

FIGURE 8: MR dampers configuration in the $x$-direction.

4.2. MR Dampers Placement with Lever Mechanism. The lever mechanism indicated in Figure 8 is used for the purpose of displacement magnification across the damper. The magnification factor (MF) is defined as

$$
\mathrm{MF}=\frac{L_{2}}{L_{1}}=\frac{x_{d}}{x_{f}}=\frac{F_{f}}{F_{d}},>1,
$$

where $L_{1}$ and $L_{2}$ are arms of the lever; $x_{d}$ is the displacement across the damper and $x_{f}=X_{f} \cos (\theta)$ in which $X_{f}$ is the shear drift between the floors connected to the damper, $\theta$ is the inclination angle of the diagonal bracing, $F_{f}$ is force acting on the floor through the diagonal bracing, and $F_{d}$ is the force produced by the damper. The symbols are indicated in Figure 8(b).

Not only can the proposed lever mechanism improve the performance of the MR dampers (as it increases the velocity across the damper and hence the amount of energy dissipated per cycle), but it also may reduce the required number of devices. However, this may increase the control force in the bracing system, hence the need for a stronger bracing link. This may be acceptable provided that a cooling system is well designed to reject the energy dissipated by the dampers.

4.3. Modal Damping Contribution of the MR Dampers. Optimization to find the best place for dampers is first carried out based on drift and modal damping contribution. Positions "between the 11th and 16th floors" and "between the 16th and 21st floors" had the highest drifts among other possible positions in the $x$-direction (Figure 5). Placement "between the 16th and 21st floors" gave the highest contribution to the first modal damping for the same amount of viscous damping over all possible placements in the $x$-direction. In the $y$-direction, however, the higher the floor level to which the bracing element is connected, the higher the contribution to the first modal damping. Note that, for this specific building, the acceleration and displacement response due to wind loads are mainly contributed by the first modes in the two lateral directions.

Due to the nonlinearity of the MR damper, it is difficult to derive mathematical formulations to give the modal parameters of the system after the dampers are implemented. An alternative is to study the decay of the system under initial 


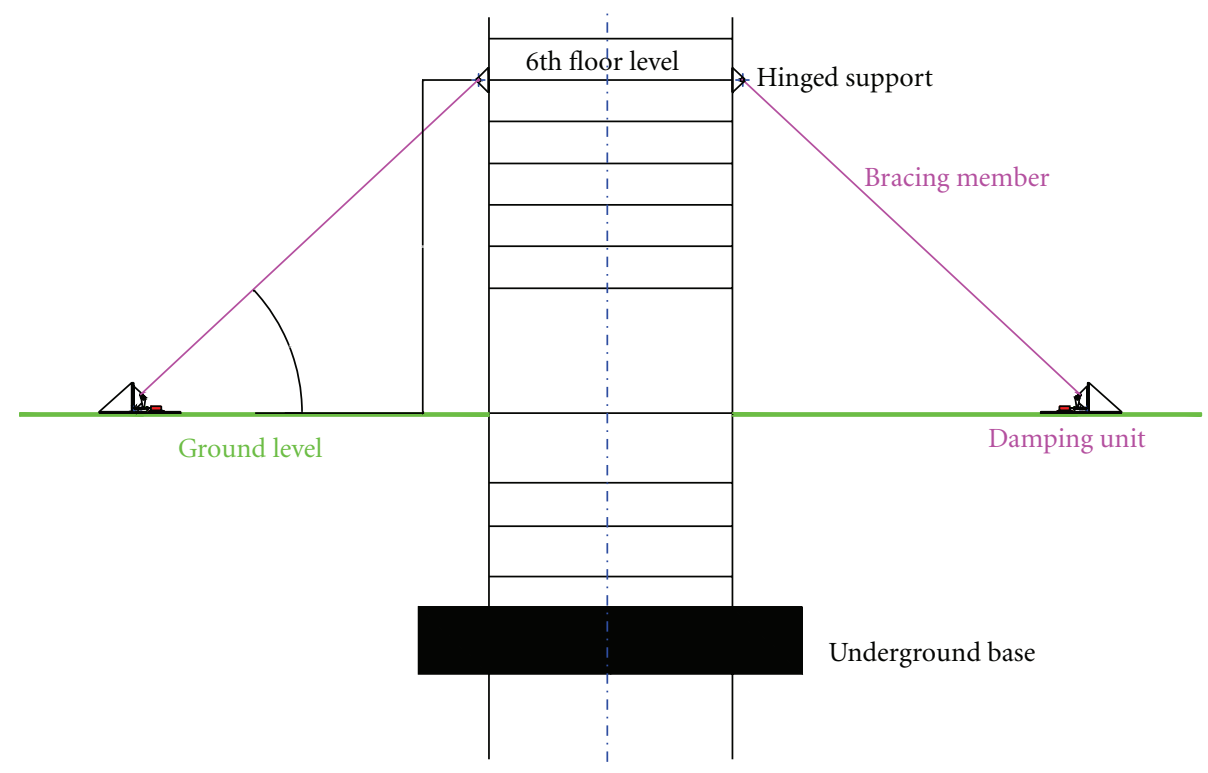

(a)

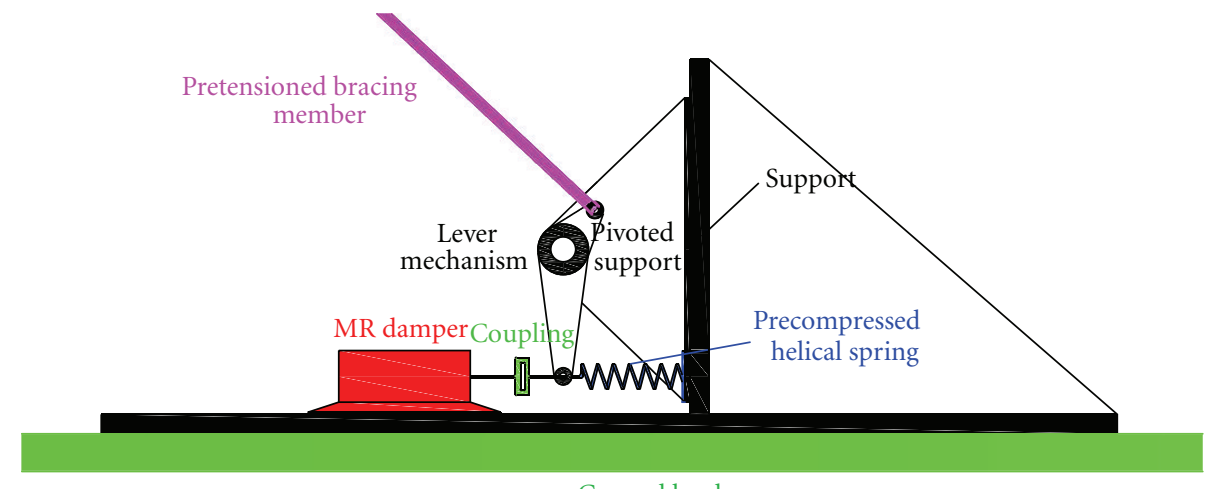

(b)

Figure 9: Analytical model for damped structure ( $y$-direction).

displacement using the SIMULINK model of the MR damper with the building model. The top floor of the building in a certain lateral direction ( $x$ or $y$ ) was given unit initial displacement, while all of the other floors were given initial displacements that were proportional to their first modal displacements in that lateral direction. To the authors' best knowledge, this helped in exciting the building mostly in its first lateral mode in the consider direction ( $x$ or $y$ ).

Two $1000 \mathrm{kN}$ MR dampers are placed between each two selected successive floors (Figure 5), then the first modal damping of the system is obtained from the response decay. Figure 10(a) shows the effect of the placement of two MR dampers with an ideal bracing system on the first modal damping and frequency of the building in the $x$-direction. The buildings damping and frequency without the addition of any dampers "w/o damp." are indicated in the figure for comparison. Effect of the magnification factor (MF) is also studied. It is shown that the highest amount of damping in the first mode is achieved with the dampers position "between the 16th and 21st floors." This means that optimization based on drift, viscous dampers, and MR dampers is giving the position "between the 16th and 21st floors" as the best position. Keeping this in mind, one can save a lot of time in running simulations with the nonlinear MR damper model. The figure shows that by increasing the magnification factor of the lever mechanism, one can have higher damping for the same number of dampers (2 MR dampers). This indicates the importance of the proposed lever mechanism. The figure also shows that the addition of MR dampers may slightly increase the undamped natural frequency of the building. The building's frequency shift increases with the increase of the MF for the same number of dampers. Dampers positioned "between the 41st and 46th" resulted in the highest frequency shift.

Four MR dampers attached to an outer bracing lever system (Figure 9) are used to reduce the building response in the $y$-direction. First, the link is assumed to be connected between the ground and one of the floors- $-1,6$, or 1 . 

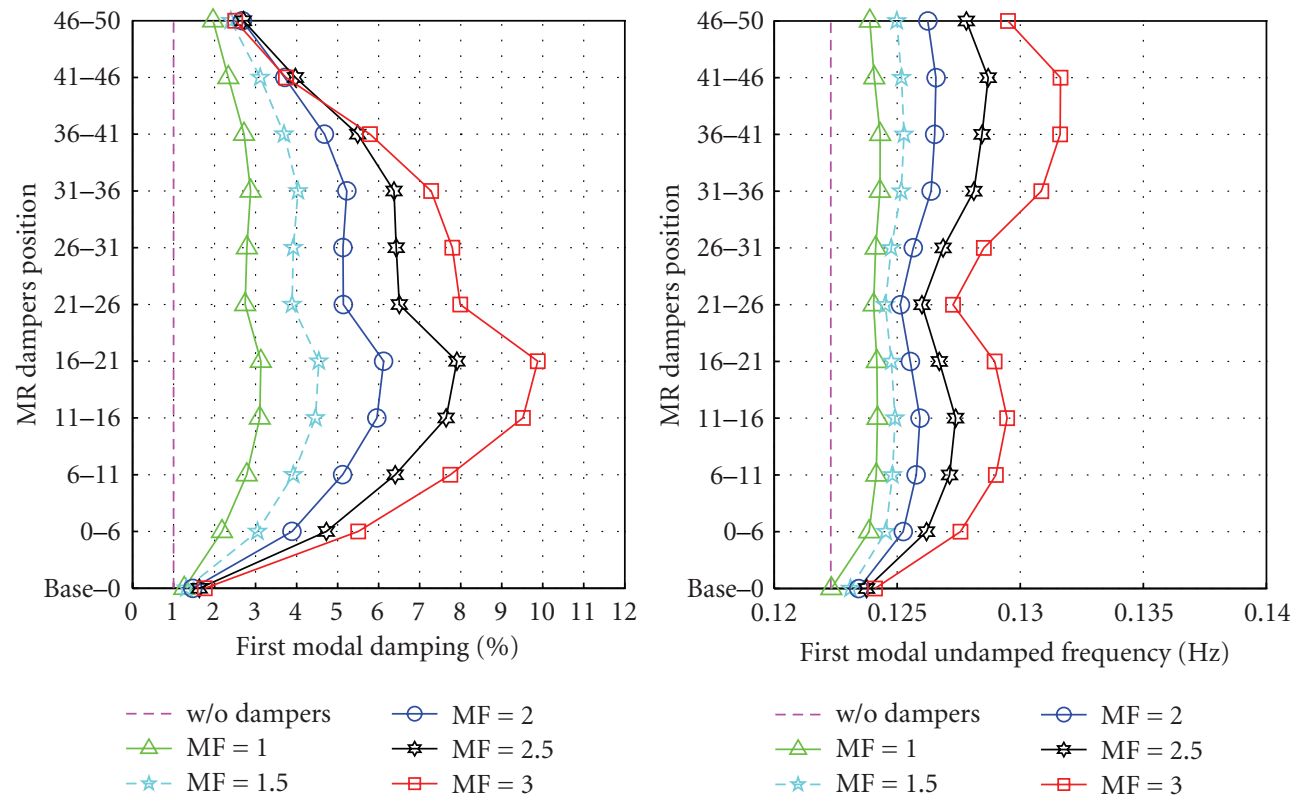

(a)

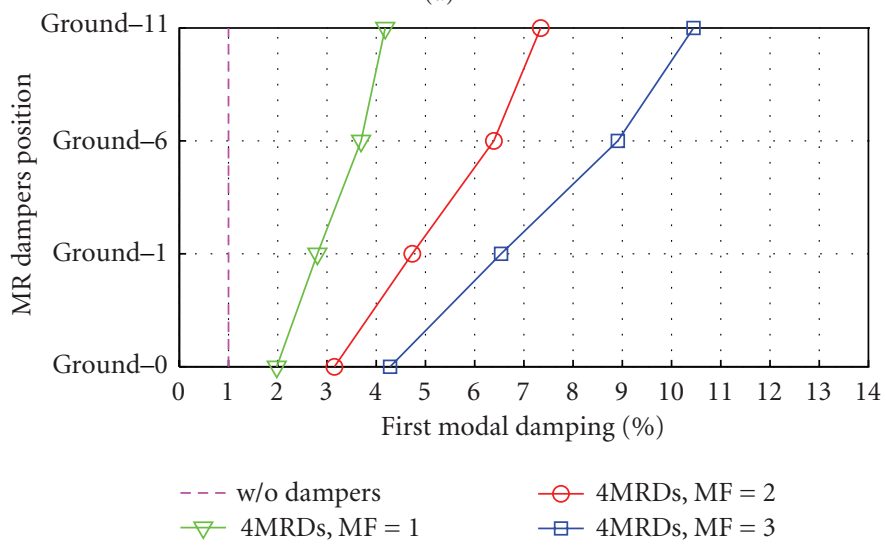

(b)

FIGURE 10: Effects of MR dampers placement on the modal parameters of the building. First modal damping (\%) refers to the amount of equivalent viscous damping that the building (with the MR dampers) has if it was oscillating in its first mode.

Figure 10(b) shows the effect of the placement of the MR dampers with an ideal outer bracing system on the first modal damping of the building. It is shown that, as the link is connected to higher floors, the first modal damping increases. In the figure, like the $x$-direction case, it is shown that, by increasing the magnification factor of the lever mechanism, one can have higher damping for the same number of dampers. Again, this indicates the importance of the proposed lever mechanism with the MR dampers.

\section{Response under Wind Loads}

5.1. Effect of Bracing Stiffness. Figure 11(a) shows the effect of bracing stiffness on the RMS and peak accelerations of the building in the $x$-direction. Two MR dampers are connected with a bracing-lever system between floors 16 and 21 . A magnification factor of 2 is used. The overall deflection in the bracing system is used as an indicator of the bracings stiffness. No deflection means an ideal bracing that is assumed to be infinitely stiff. By reducing the overall stiffness of the bracing system (by allowing for higher allowable stress), the overall bracings deflection can be increased. In the figure, "uncontrolled" means the acceleration response of the building without the control system. "Design limit" refers to the maximum RMS and peak acceleration levels allowed by the owner of the building. "Passive-on" means that the input voltage to the current driver of the MR dampers is set to the maximum value (constant input voltage). "Decentralized" means that the input voltage was changeable during the simulation according to the decentralized bangbang controller.

Figure 11(a) shows that, by using a bracing system with higher deflections, the performance of the passive-on case is decreased. However, the decentralized bang-bang controller shows better performance over the passive-on case at higher 

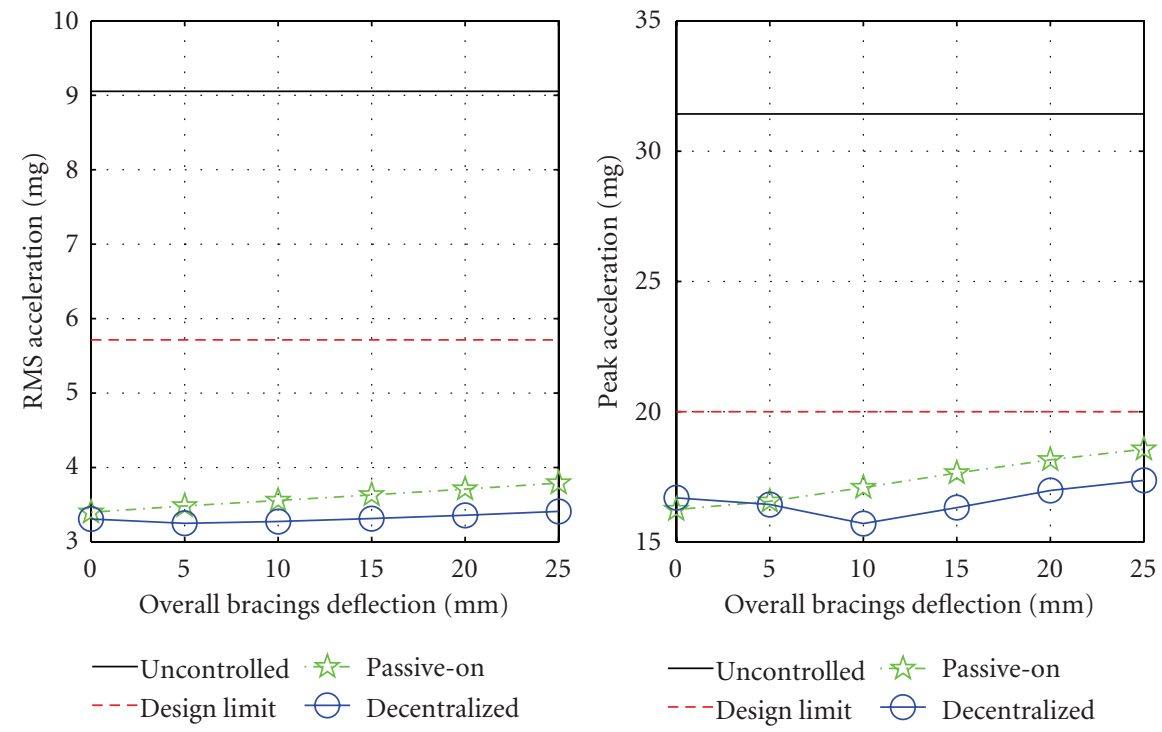

(a)
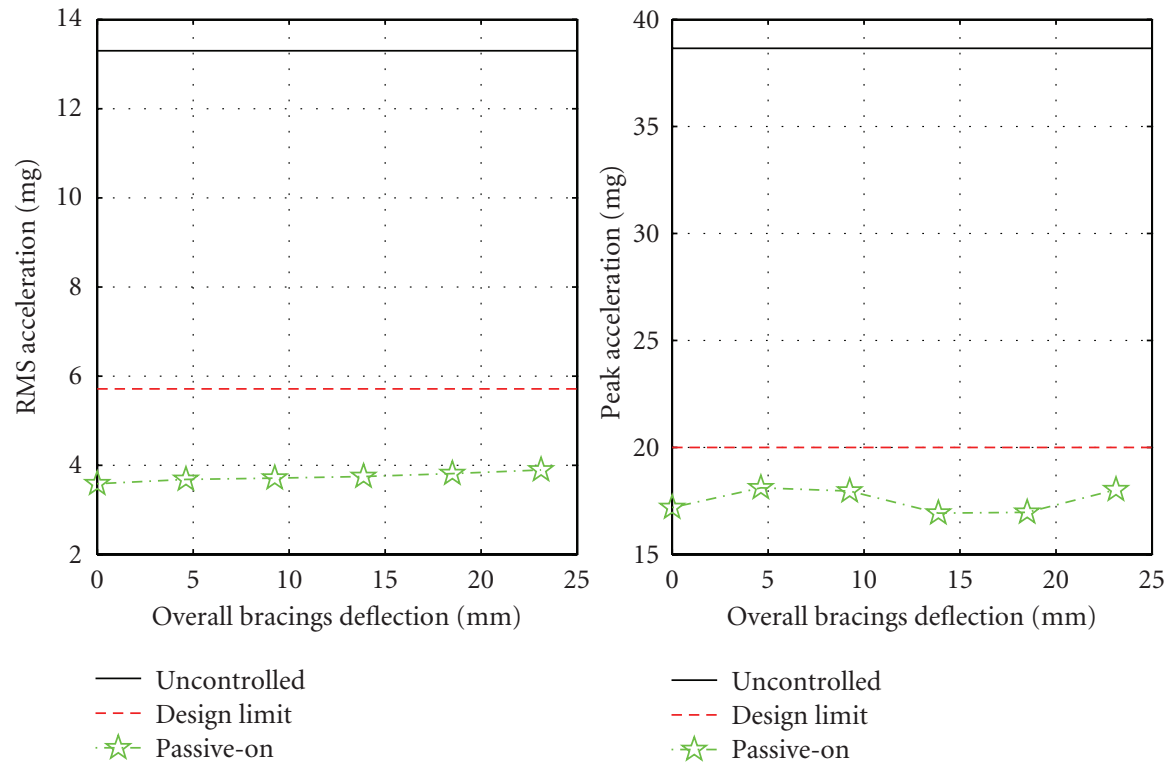

(b)

FIGURE 11: Effects of bracing stiffness on the performance of the MR dampers.

bracings deformation (lower stiffness). For an ideal bracing system, the decentralized bang-bang controller is not much better at reducing the RMS acceleration over the passive-on case and results in higher peak acceleration. The reason for this is the shock caused by the damper as the decentralized bang-bang controller tends to change the input voltage from 0 to the maximum value. This may increase the building's instantaneous acceleration if the bracings system is considered ideal. At the same time, if the bracing system has some elasticity (which is the practical case), the bracing acts as a spring between the damper and the building's floor hence reduces the shock caused by the MR damper on the floor. The use of a bracing system with lower stiffness decreases the efficiency of the MR damper in reducing RMS accelerations for both of the passive-on and the decentralized bang-bang controller. The reduction in the bracings stiffness tends to reduce the peak acceleration up to a certain limit of the bracing stiffness $(10 \mathrm{~mm}$ overall deflection which corresponds to $80 \mathrm{MPa}$ allowable stress) when the decentralized bang-bang controller is used. After this limit of bracing stiffness, the reduction in the bracing stiffness reduces the performance of the MR damper. However, the decentralized bang-bang controller improves the response reduction. 


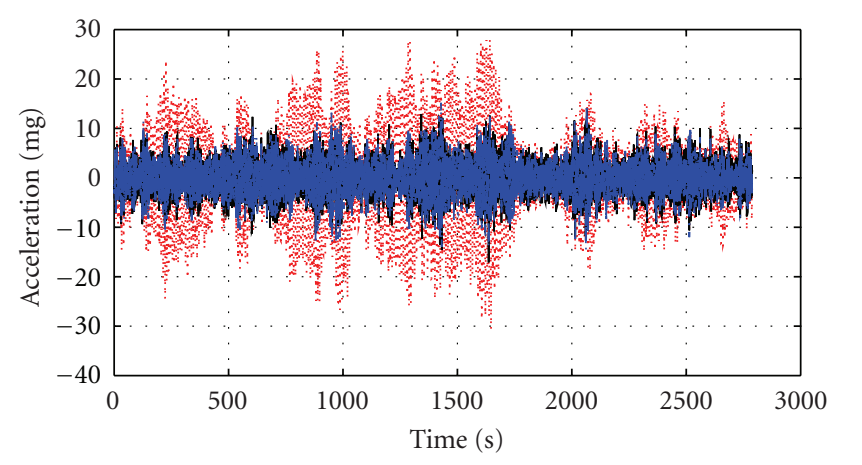

.... Uncontrolled
- Passive-on
..-- Decentralized

Figure 12: Time history of the uncontrolled and controlled acceleration response of the last floor in the $x$-direction.

Figure 11(b) shows the effect of bracing stiffness on the RMS and peak accelerations of the building in the $y$ direction. Four MR dampers are connected with a bracinglever system (Figure 9) between the ground and floor 6 . A magnification factor of 3 is used. The overall deflection in the bracing system is used as an indicator of the bracings stiffness. No deflection means an ideal bracing that is assumed to be infinitely stiff and able to carry both tension and compression. The stiffness of the helical spring (Figure 9(b)) is selected such that it will be able to give a sufficient pretension in the bracing member and is assumed to be constant. This is to allow the damper to work properly all the time (i.e., to provide damping whenever the floor is moving to the right or to the left). Again, it is shown that, by using a bracing system with higher deflections, the performance of the passive-on case in reducing the RMS acceleration is decreased. However, peak acceleration has no constant trend. It is increased, then decreased, and increased again.

\subsection{Numerical Results and Discussion}

5.2.1. Response in the $x$-Direction. To examine the effect of the MR dampers on the other responses of the building ( $x$-direction), a bracing system with an overall deflection of $15 \mathrm{~mm}$ is used (about $120 \mathrm{MPa}$ working stress). The responses of the building under the wind attack angle of $292.5^{\circ}$ are considered. This wind attack angle is shown to give the highest acceleration and displacement responses in the $x$-direction over all of the other possible wind attack angles [25]. Figure 12 gives the time history of the acceleration of the last floor for the uncontrolled, passive-on case, and the decentralized bang-bang controller. The figure shows the capability of the MR damper in reducing the buildings acceleration under strong wind loads for a time period of about 1 hour.

Due to possible changes in the buildings' natural frequencies during its service life $[29,30]$, uncertainty in the stiffness of the building of $\pm 10 \%$ is considered. Table 2 gives the uncontrolled and controlled responses of the building in the $x$-direction. For comfort and security reasons, mean wind speed that corresponds to a return period of 10 years and 100 years is used, respectively. For comfort reasons, RMS and peak values of the acceleration are considered in the comparison. For security, the RMS and the peak values of the displacement at the top of the building, the RMS and the peak values of maximum interstory drift, the RMS and the peak values of the shear loads (SL) at the ground level, and the RMS and the peak values of the bending moment (BM) at the ground level are considered. In the table, " $0 \%$ stiffness" means the building with the original stiffness, " $+10 \%$ stiffness" means the building with $10 \%$ increase in the original stiffness, and "-10\% stiffness" means the building with $10 \%$ reduction in the original stiffness. Percentages of response reduction for the case of " $0 \%$ stiffness" are indicated in the table (between brackets).

Under wind loads with a return period of 10 years, MR dampers with both passive-on and decentralized bang-bang controller are able to bring the acceleration responses lower than the maximum allowable values (RMS acceleration = 5.7 milli-g and peak acceleration $=20$ milli-g). However, the decentralized bang-bang controller is shown to work better than the passive-on case in reducing the RMS accelerations for the assumed buildings stiffness uncertainty. This indicates the robustness of the decentralized bangbang controller. For the building with the original stiffness, decentralized bang-bang controller is able to reduce the RMS and peak accelerations by about $4.4 \%$ and $6.2 \%$, respectively. However, for " $+10 \%$ stiffness" and " $-10 \%$ stiffness" passiveon is better in reducing the peak accelerations. Under wind loads with a return period of 100 years, MR dampers with both passive-on and decentralized bang-bang controller are capable of reducing the responses of the building. Decentralized bang-bang controller is shown to be better than the passive-on in reducing all of the responses except for the RMS interstory drift angle for the case "-10\% stiffness" which is slightly higher than the passive-on case.

5.2.2. Response in the $y$-Direction. To see the effect of the MR dampers on the responses of the building in the $y$-direction, a bracing system with an overall deflection of $15 \mathrm{~mm}$ is used (about $120 \mathrm{MPa}$ working stress). The responses of the building under the wind attack angle of $0^{\circ}$ are considered. This wind attack angle was shown to give the highest acceleration and displacement responses in the $y$-direction [25]. Uncertainty in the stiffness of the building of $\pm 10 \%$ is considered.

Table 3 gives the uncontrolled and controlled responses of the building in the $y$-direction. Under wind loads with a return period of 10 years, MR dampers with both passiveon and decentralized bang-bang controller are able to bring the RMS and peak accelerations lower than the maximum allowable values for the assumed uncertainty in the buildings stiffness except for the "-10\% stiffness" with the decentralized controller where the peak acceleration is slightly higher. However, this may be accepted as the RMS accelerations are much lower than the maximum allowable value 5.7 millig). Again, like the $x$-direction, the decentralized bang-bang controller is performing better than the passive-on case 


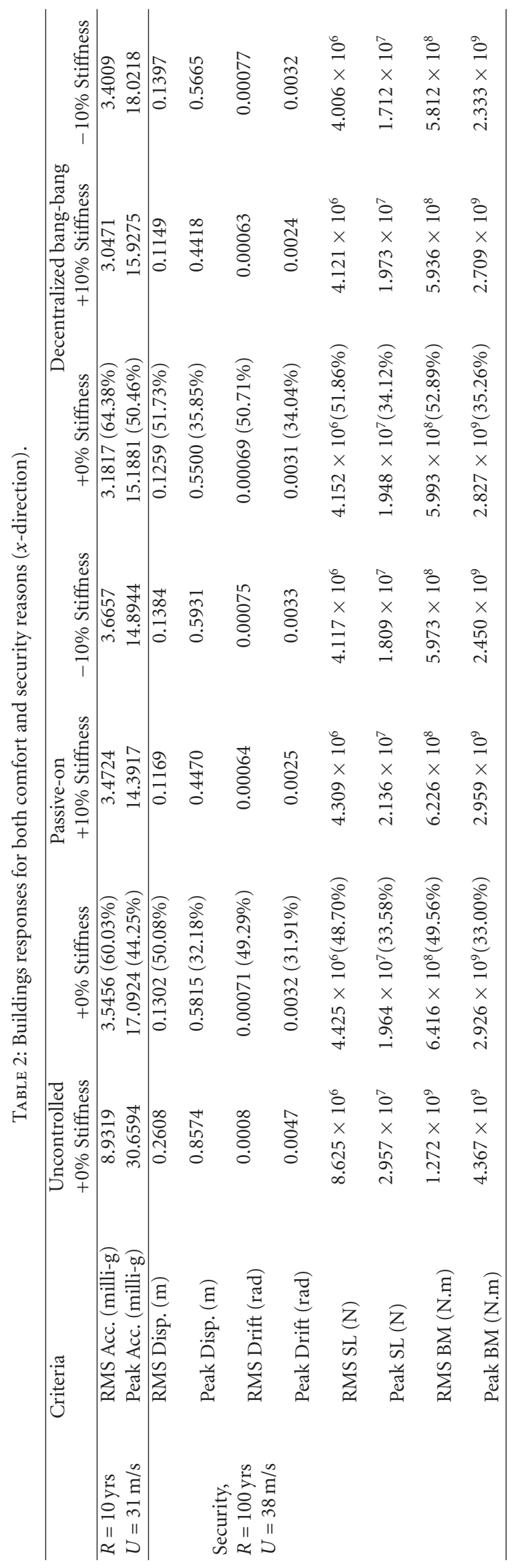




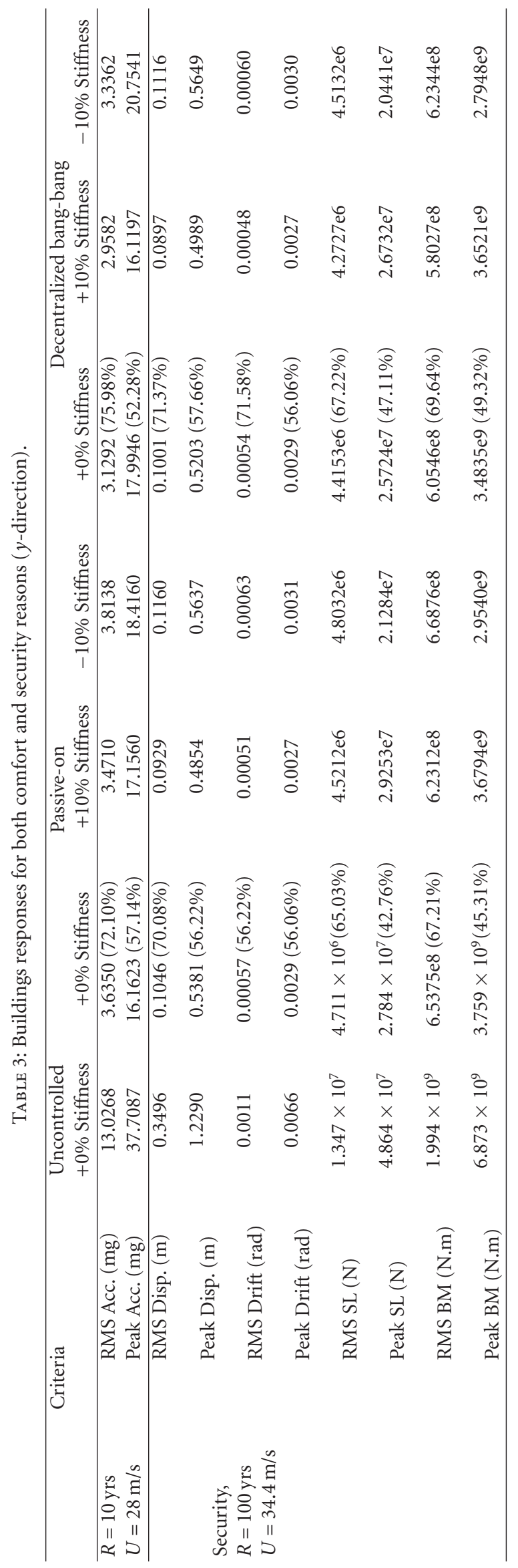


in reducing RMS acceleration values for the building with stiffness uncertainties which indicates the robustness of this controller.

Under wind loads with a return period of 100 years, MR dampers with both passive-on and decentralized bang-bang controller are able to give good reductions in the responses of the building in the range of $42.76 \%$ to $71.56 \%$. Decentralized bang-bang controller is better than the passive-on in reducing all of the RMS responses. In addition, this controller is able to reduce the peak shear loads (SLs) and the peak bending moment (BM) over the passive-on case.

\section{Concluding Remarks}

With many advantages over TMDs and ATMDs, smart dampers are used in this paper to reduce the vibrations of a tall building in the two lateral directions. Optimization was done to find the best position for the MR dampers in the two lateral directions. Results show that the best position of viscous dampers based on drift and modal damping maximization is also the best position for the MR damper. Keeping this in mind, one can save a lot of time in running simulations with the nonlinear MR damper model.

New bracings-lever mechanism configurations are proposed to improve the performance of the dampers. Results show that the proposed control system with the new configurations is very effective in reducing the capacity and number of dampers required. It is shown that the decentralized bang-bang controller with the MR damper may slightly improve the performance over the passive-on case for an ideal bracing system. Therefore, when the bracings were designed to allow for some deformations (practical case), the performance of the decentralized controller over the passiveon was increased. This means that semiactive controller's effectiveness is dependent on the stiffness of the bracing system. However, the methodology developed in this paper permits the acceleration levels and design forces of tall buildings under winds to be controlled and assessed at the preliminary design stages. follows.

The contributions of this paper can be summarized as

(1) For the purpose of using MR dampers for vibration reduction in buildings, it is recognized that shear response and flexural response of tall buildings present two very different cases for vibration suppression.

(2) A lever mechanism can enable application to flexural response and scenarios where the interstory drift is not enough for dampers to work effectively.

(3) A comparison of on/off control to full-time application may be insightful.

In spite of the great advantages of MR dampers over TMDs and ATMDs, the outer bracings in the $y$-direction may not be generalized for similar tall buildings if there is space limitation. In such case, ATMD is a possible alternative. Nevertheless, the proposed control system in the $x$-direction is an excellent choice.

\section{References}

[1] T. T. Soong, Active Structural Control: Theory and Practice, John Wiley \& Sons, 1990.

[2] J. C. Wu and B. C. Pan, "Wind tunnel verification of actively controlled high-rise building in along-wind motion," Journal of Wind Engineering and Industrial Aerodynamics, vol. 90, no. 12-15, pp. 1933-1950, 2002.

[3] L. T. Lu, W. L. Chiang, J. P. Tang, M. Y. Liu, and C. W. Chen, "Active control for a benchmark building under wind excitations," Journal of Wind Engineering and Industrial Aerodynamics, vol. 91, no. 4, pp. 469-493, 2003.

[4] A. M. Aly, F. Resta, and A. Zasso, "Active control in a high-rise building under multidirectional wind loads," in Proceedings of the Structures Congress, vol. 314, Vancouver, Canada, April 2008.

[5] A. M. Aly, A. Zasso, and F. Resta, "Dynamics and control of high-rise buildings under multidirectional wind loads," Smart Materials Research, vol. 2011, Article ID 549621, 15 pages, 2011.

[6] R. J. Smith and M. R. Willford, "The damped outrigger concept for tall buildings," Structural Design of Tall and Special Buildings, vol. 16, no. 4, pp. 501-517, 2007.

[7] S. J. Dyke, B. F. Spencer, M. K. Sain, and J. D. Carlson, "Modeling and control of magnetorheological dampers for seismic response reduction," Smart Materials and Structures, vol. 5, no. 5, pp. 565-575, 1996.

[8] H. Metwally, B. El-Souhily, and A. Aly, "Reducing vibration effects on buildings due to earthquake using magnetorheological dampers," AEJ - Alexandria Engineering Journal, vol. 45, no. 2, pp. 131-140, 2006.

[9] A. M. Aly and R. E. Christenson, "On the evaluation of the efficacy of a smart damper: a new equivalent energy-based probabilistic approach," Smart Materials and Structures, vol. 17, no. 4, Article ID 045008, 2008.

[10] A. M. Aly, A. Zasso, and F. Resta, "On the dynamics of a very slender building under winds: response reduction using MR dampers with lever mechanism," Structural Design of Tall and Special Buildings, vol. 20, no. 5, pp. 539-551, 2011.

[11] M. C. Constantinou, P. Tsopelas, and W. Hammel, “Testing and modeling of an improved damper configuration for stiff structural systems," Tech. Rep., Center for Industrial Effectiveness and Taylor Devices, 1998.

[12] C. H. Huang, "Parametric study for motion amplification device with viscous damper," in the 13th World Conference on Earthquake Engineering, Vancouver, Canada, 2004.

[13] R. J. McNamara and D. P. Taylor, "Fluid viscous dampers for high-rise buildings," Structural Design of Tall and Special Buildings, vol. 12, no. 2, pp. 145-154, 2003.

[14] A. N. Sigaher and M. C. Constantinou, "Scissor-jack-damper energy dissipation system," Earthquake Spectra, vol. 19, no. 1, pp. 133-158, 2003.

[15] S. Berton and J. E. Bolander, "Amplification system for supplemental damping devices in seismic applications," Journal of Structural Engineering, vol. 131, no. 6, pp. 979-983, 2005.

[16] S.-H. Lee, K.-W. Min, L. Chung et al., "Bracing systems for installation of MR dampers in a building structure," Journal of Intelligent Material Systems and Structures, vol. 18, no. 11, pp. 1111-1120, 2007.

[17] K. K. Walsh, K. J. Cronin, M. D. Rambo-Roddenberry, and K. Grupenhof, "Dynamic analysis of seismically excited flexible 
truss tower with scissor-jack dampers," Structural Control and Health Monitoring. In press.

[18] N. Satake, K. I. Suda, T. Arakawa, A. Sasaki, and Y. Tamura, "Damping evaluation using full-scale data of buildings in Japan," Journal of Structural Engineering, vol. 129, no. 4, pp. 470-477, 2003.

[19] Y. Tamura and A. Yoshida, "Amplitude dependency of damping in buildings," in Proceedings of the 18th Analysis and Computation Speciality Conference, vol. 315, Vancouver, Canada, April 2008.

[20] S. Attaway, Matlab: A Practical Introduction to Programming and Problem Solving, Butterworth-Heinemann, Amsterdam, The Netherlands, 2009.

[21] I. Chowdhury and S. P. Dasgupta, "Computation of Rayleigh damping coefficients for large systems," Electronic Journal of Geotechnical Engineering, vol. 8, 2003.

[22] L. Meirovitch, Analytical Methods in Vibrations, The Macmillan Co., New York, NY, USA, 1967.

[23] G. Diana, S. De Ponte, M. Falco, and A. Zasso, "A new large wind tunnel for civil-environmental and aeronautical applications," Journal of Wind Engineering and Industrial Aerodynamics, vol. 74-76, pp. 553-565, 1998.

[24] Eurocode 1, "Eurocode 1: Actions on structures-General actions - Part 1-4: Wind actions," prEN 1991-1-4: European Standard, 2004

[25] A. M. Aly, On the dynamics of buildings under winds and earthquakes: response prediction and reduction, Ph.D. thesis, Department of Mechanical Engineering, Politecnico di Milano, Milan, Italy, 2009.

[26] F. Yi, S. J. Dyke, J. M. Caicedo, and J. D. Carlson, "Seismic response control using smart dampers," in Proceedings of the American Control Conference (ACC '99), pp. 1022-1026, June 1999.

[27] A. Khaje-Karamodin, H. Haji-Kazemi, A. R. Rowhanimanesh, and M. R. Akbarzadeh-Tootoonchi, "Semi-active control of structures using a neuro-inverse model of MR dampers," Scientia Iranica, vol. 16, no. 3, pp. 256-263, 2009.

[28] S. J. Dyke and B. F. Spencer Jr., "A comparison of semi-active control strategies for the MR damper," in Proceedings of the IASTED International Conference on Intelligent Information Systems (IIS '97), Grand Bahama Island, Bahamas, December 1997.

[29] K. V. Yuen and S. C. Kuok, "Ambient interference in long-term monitoring of buildings," Engineering Structures, vol. 32, no. 8, pp. 2379-2386, 2010.

[30] K. V. Yuen and S. C. Kuok, "Modeling of environmental influence in structural health assessment for reinforced concrete buildings," Earthquake Engineering and Engineering Vibration, vol. 9, no. 2, pp. 295-306, 2010. 

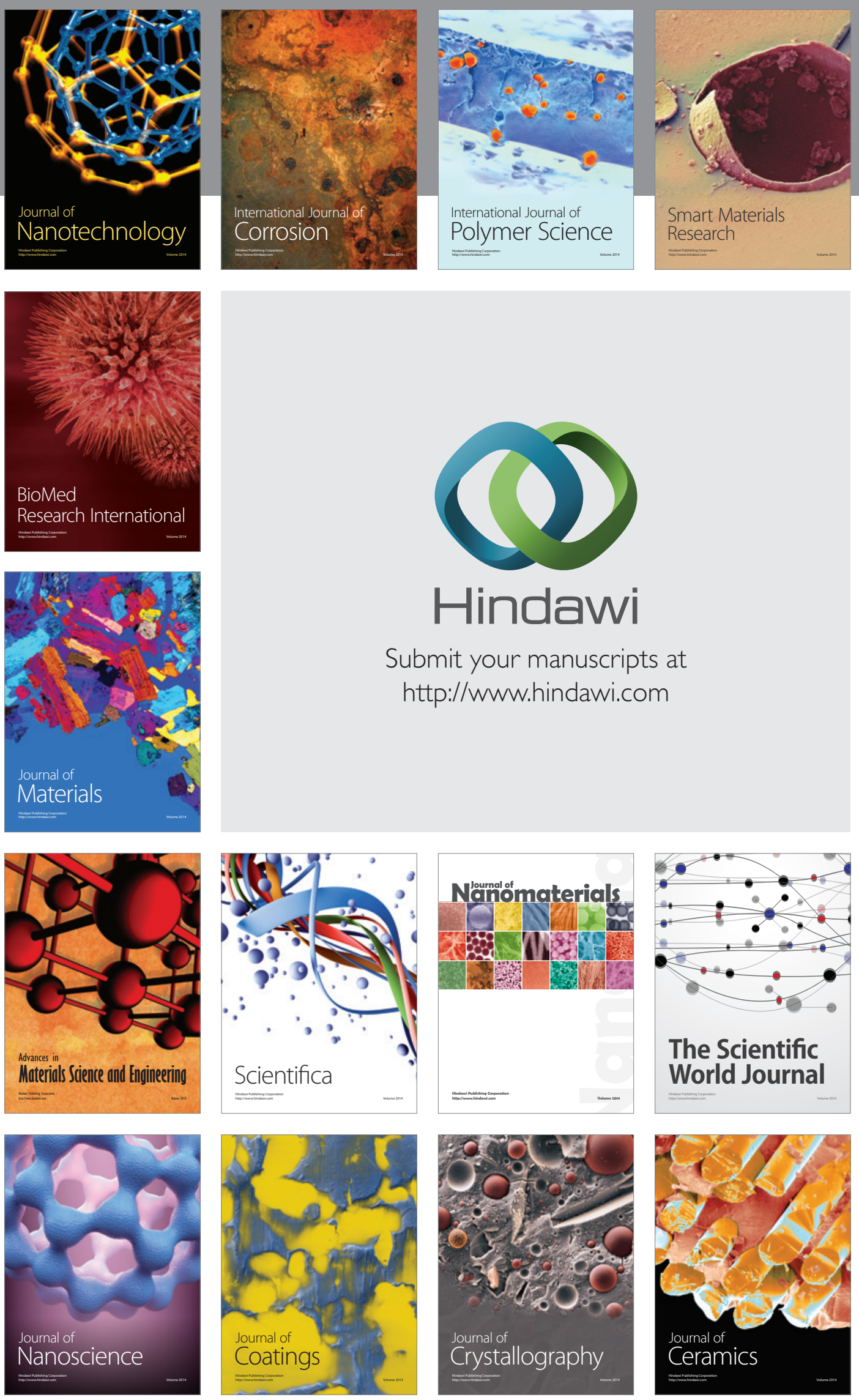

The Scientific World Journal

Submit your manuscripts at

http://www.hindawi.com

\section{World Journal}

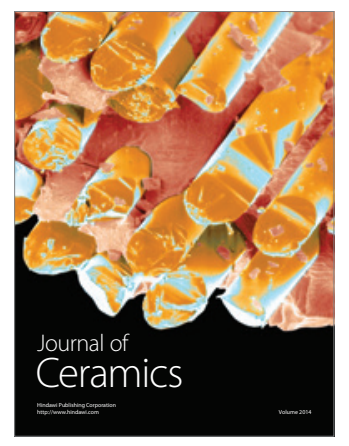

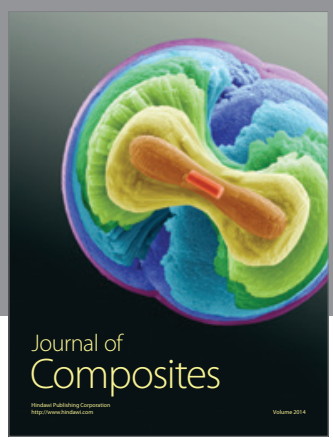
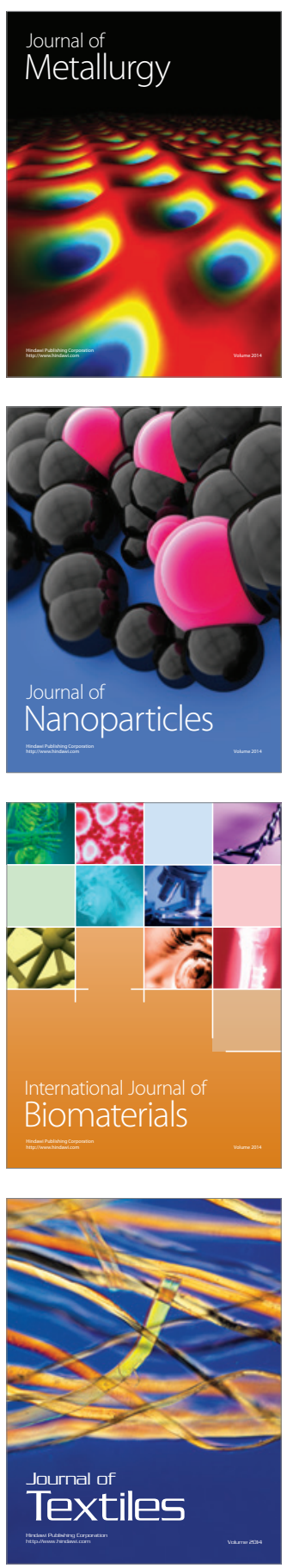